\title{
A Decade of Successful Collaborations in Nutritional Compound Process Research and Development
}

Werner Bonrath, Roman Goy, Ulla Létinois, Marc-André Müller, Thomas Netscher, Jan Schütz, and Jonathan A. Medlock*

\begin{abstract}
Collaborations between academia and industry are vital for modern industrial research and development projects, combining the best of both worlds to develop sustainable chemical processes. Herein we summarize a number of successful cooperations between DSM Nutritional Products and Swiss academic institutions that have been carried out over approximately the past decade. A wide variety of reactions and processes have been investigated with experts located in Switzerland. New synthetic routes, chemical transformations and reactor concepts have been developed to produce industrially relevant compounds. Additionally the scope of known catalytic systems has been probed and new catalysts showing improved selectivity have been designed, synthesized and tested. We describe how the research was supported by DSM, the parallel in-house investigations and also how the projects were continued and further developed.
\end{abstract}

Keywords: Catalysis · Fine chemicals · Nutritional ingredients · Sustainable chemical processes · Vitamins

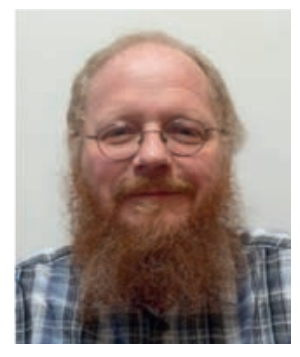

Werner Bonrath studied chemistry at the universities of Bonn and Münster. He received his $\mathrm{PhD}$ at Max-Planck-Institute für Kohlenforschung and University of Bochum and his habilitation in Technical Chemistry at the University of Jena. He started his industrial career in 1989 and is now Senior Science Fellow for catalysis and process research at DSM.

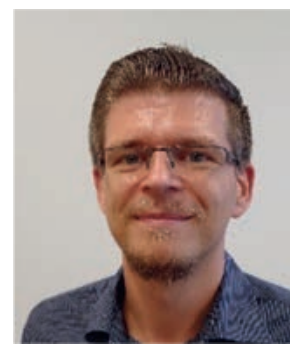

Roman Goy studied chemistry at the University of Jena and then stayed there to complete his $\mathrm{PhD}$ in the group of Prof. W. Weigand. He started his industrial career in 2015 as a postdoc at DSM Nutritional Products in Kaiseraugst $(\mathrm{CH})$ working on heterogeneous catalysis. He is currently working as a Scientist at DSM with the focus on process research, especially in the areas of electrochemical reactions and membrane-related separations.

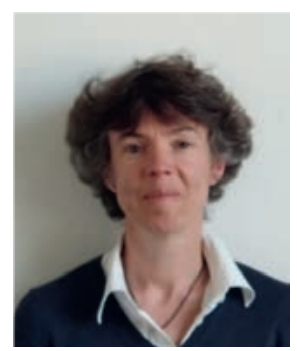

Ulla Létinois received her $\mathrm{PhD}$ in the frame of the European Doctoral College in Organic Chemistry from the University Louis Pasteur Strasbourg (F) and from the University of Leipzig (D) in 2003. After postdoctoral stays with Prof. B. Meunier in Toulouse (F) and Prof. J.-P. Sauvage in Strasbourg (F), she started working at DSM Nutritional Products in Kaiseraugst $(\mathrm{CH})$ in 2005. Since then her focus is on sustainable chemistry and Life Cycle Assessments of chemical and fermentative processes.

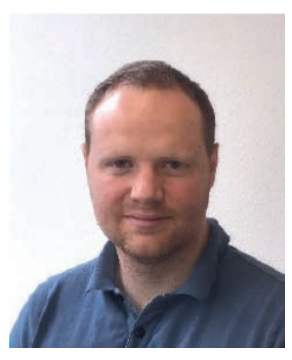

Marc-André Müller received his $\mathrm{PhD}$ from the University of Basel in the group of Prof. A. Pfaltz followed by a post-doctoral stay at the Max-Planck-Institute für Kohlenforschung with Prof. A. Fürstner. He started his industrial career at Dottikon ES where he was chemist in the high-pressure lab. Currently he is working at DSM in the field of process research.

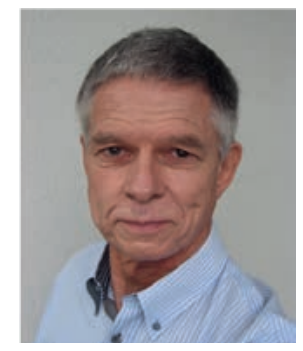

Thomas Netscher studied chemistry at the Universities of Constance and Freiburg i.Br. (D) working with Prof. H. Prinzbach to obtain a $\mathrm{PhD}$ in organic synthesis. He started his industrial career at Roche in Basel, with a stay at the Roche Research Center in Nutley, New Jersey (USA). He worked as a Principal Scientist at DSM mainly on isoprenoids and lipid-soluble vitamins until his retirement last year. He has held the Roche Lectureship (Europe, 1997/98), is recipient of the Sandmeyer Award (2008) and the Senior Industrial Investigator Award (2017) of the Swiss Chemical Society, and served as a Lehrbeauftragter in organic chemistry at the University of Freiburg i.Br.

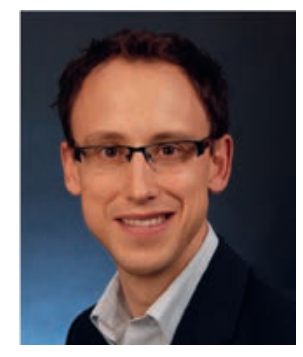

Jan Schütz works as a Senior Scientist at DSM Nutritional Products in Kaiseraugst, Switzerland. He is active in the research and development of organic syntheses of vitamins, nutraceuticals, and fragrance compounds. Special focus is on steroid syntheses regarding vitamin $\mathrm{D}$ and its derivatives and on heterogeneous catalysis in general, with focus on gas phase chemistry. Prior to joining DSM in 2005 he obtained his $\mathrm{PhD}$ in chemistry in the group of Prof. W. A. Herrmann at the Technical University of Munich, investigating the application of alternative $N$-heterocyclic carbene-metal complexes in homogeneous catalysis. 


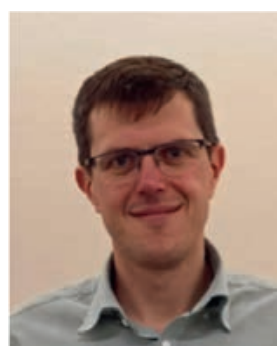

Jonathan Medlock studied natural science at Cambridge University (UK) and then stayed there to complete a $\mathrm{PhD}$ in synthetic organic chemistry with Prof. S. Warren. After a postdoc at the University of Basel with Prof. A. Pfaltz and working in the catalysts group of Johnson Matthey (UK), he is now a process chemist at DSM specializing in catalysis, especially hydrogenation reactions.

\section{Introduction}

The driving force for chemical process research, especially in the fine chemicals' industry, is the development of sustainable, efficient and low-cost production processes for a wide variety of compounds and products. An advantage and challenge of working in the area of vitamins, nutritional ingredients, personal care and aroma chemicals is that many of the active molecules have an eternal lifetime. That is, they have been known and produced for many years (and even decades) and will continue to be needed in the future. Therefore improved processes are always required, but the target is already set very high by the vast amount of existing knowledge of the current systems. In addition, there are always further, as yet uncommercialized compounds, that show a nutritional benefit to both humans and animals, where the development of novel, efficient syntheses is also required. Due to tight project timelines, or perhaps limited existing experience and know-how, it is not always possible or even sensible to investigate all potential ideas in-house. Therefore there is the need to work with experts outside DSM in certain fields. Given the strength and breadth of scientific knowledge in Switzerland, the vast majority of DSM's collaborations in process chemistry can be fulfilled by scientists "just around the corner".

Rather than focus on one particular cooperation, what we have aimed to do in this article is to highlight some of the collaborations undertaken in approximately the past ten years in the field of process research. These projects were initiated for a variety of reasons such as: investigating a specific transformation that was relevant to a running R\&D project at DSM, obtaining more indepth understanding of a particular class of reactions or catalysts where there was limited existing in-house knowledge or testing new technologies and emerging fields for relevance to DSM, and fundamental investigations that would hopefully lead to a stepchange in chemical production. In all cases we have sought out local experts in their field for collaborations. In addition, DSM is also approached by academics working in a particular area who are interested in applying their research to DSM's products. Sometimes a mutual project with DSM-funded investigations is initiated immediately; in other cases the collaboration starts slowly by providing materials or analytic recommendations and then grows to a cooperation with masters and $\mathrm{PhD}$ students, and postdocs.

\section{Heterogeneous Hydrogenation}

Catalytic hydrogenation reactions are widely used in all areas of industrial chemical synthesis and are of particular importance in the manufacture of fine chemicals such as vitamins, carotenoids and aroma compounds. ${ }^{[1]}$ During the past decades a number of different hydrogenation processes have been developed and implemented, generally using commercial catalysts. One area of particular importance to DSM is the use of selective hydrogenation, such as the reduction of only one functional group in the presence of several others, and especially important, the semi-hydrogenation of alkynes to alkenes (Scheme 1). The search for the next generation of catalysts and hydrogenation processes has been a particularly active area for collaborations, both within Switzerland and elsewhere in Europe.

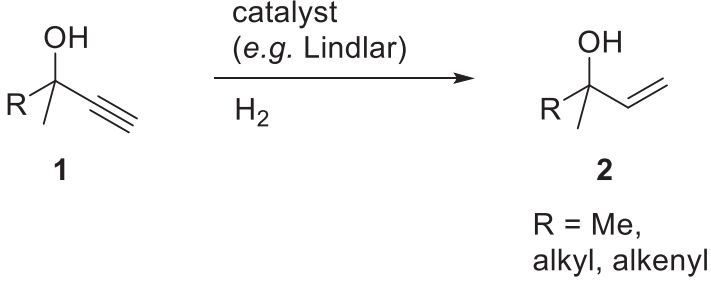

Scheme 1. An example of industrially relevant semi-hydrogenations of alkynes to alkenes.

The traditional catalyst of choice for alkyne semi-hydrogenation is the Lindlar catalyst, which is palladium deposited on a calcium carbonate support, doped with lead. ${ }^{[2]}$ Obtaining high selectivity at high conversions is a particular challenge as competing over-hydrogenation (conversion of the alkene to the corresponding alkane) can occur before the starting alkyne is completely consumed. Whilst the Lindlar catalyst can be incredibly effective, the need for sustainable manufacturing methods requires the replacement of compounds and catalysts, such as those containing lead, with more environmentally friendly alternatives. In addition, the replacement of a batch process with a continuous one would result in significant benefits such as energy recovery and throughput. Therefore DSM has been collaborating with a number of academic institutions throughout Europe in recent years to develop new types of catalysts and catalytic reactors, for example catalysts on porous glass supports, ${ }^{[3]}$ and use of alternative enabling technologies such as ultrasound and microwaves for both the catalyst preparation ${ }^{[4]}$ and in a hydrogenation reactor. ${ }^{[5]}$

Focusing on joint research projects carried out within Switzerland, the reaction kinetics of the methylbutynol hydrogenation to methylbutenol (Scheme $1 . \mathbf{1} \rightarrow \mathbf{2}, \mathrm{R}=\mathrm{Me}$ ), an important starting point for the manufacture of vitamins $\mathrm{A}$ and $\mathrm{E}$ and many other products of relevance to DSM, was studied in detail with the group of Prof. L. Kiwi-Minsker at EPFL. ${ }^{[6]}$ The key findings of this study were that the experimental data obtained under the kinetic regime were consistent with the Langmuir-Hinshelwood mechanism. The high alkene selectivity was explained by the two orders of magnitude higher adsorption constant of the alkyne to the catalyst surface, compared with the corresponding alkene. Furthermore, new catalysts for the selective hydrogenation of alkynols (such as methylbutynol) were developed. These catalysts are based on structured sintered metal fibres (SMF), which were coated with an oxide layer of $\mathrm{ZnO}$ and/or $\mathrm{Al}_{2} \mathrm{O}_{3}$. Pd-nanoparticles, which act as the active hydrogenation catalyst, were then deposited on the oxide layer. ${ }^{[7]}$ The main advantages of these catalysts are that they show high activity and selectivity and additionally are $\mathrm{Pb}$-free and have low $\mathrm{Pd}$-loadings (around $0.5 \%$ compared with $5 \%$ for a typical Lindlar catalyst). A modified version of these catalysts allowed the selective and sequential hydrogenation of polyenones (hydrogenation of $\mathrm{C}=\mathrm{C}$ bonds) (Scheme 2). ${ }^{\left[{ }^{[]}\right.}$The double bond in the $\gamma, \delta$-position is hydrogenated initially, followed by the one in the $\alpha, \beta$-position; the isolated double bond at the end of the chain is left predominantly untouched. Hydrogenation reactions with these types of catalyst are carried out at $40-230{ }^{\circ} \mathrm{C}$, up to 20 bar pressure and under solvent-free conditions.

A further collaboration in the area of selective semi-hydrogenation of alkynes focused on the development of not only an improved catalyst, but also an improved reactor concept to ensure excellent two-phase mixing between the alkyne and hydrogen gas. A 3D printed porous structured reactor was developed by the group of Prof. P. Rudolf von Rohr at ETH Zurich ${ }^{[9]}$ and a suitable catalytic coating was developed at DSM and successfully transferred to the $1^{\text {st }}$ and $2^{\text {nd }}$ generation tubular reactors.

Initially, metal alloy-based powdered catalysts were used as a prototype for the catalyst development at DSM. The improved 
<smiles>C=C(/C=C/C(C)=O)CCC=C(C)C</smiles>

preparation procedure was extended to two different designs of structured reactors, called the porous and triangular structures (Fig. 1), which were developed within the project, and tested in the continuous semi-hydrogenation of methylbutynol $(\mathbf{1}, \mathrm{R}=\mathrm{Me}) .^{[10]}$
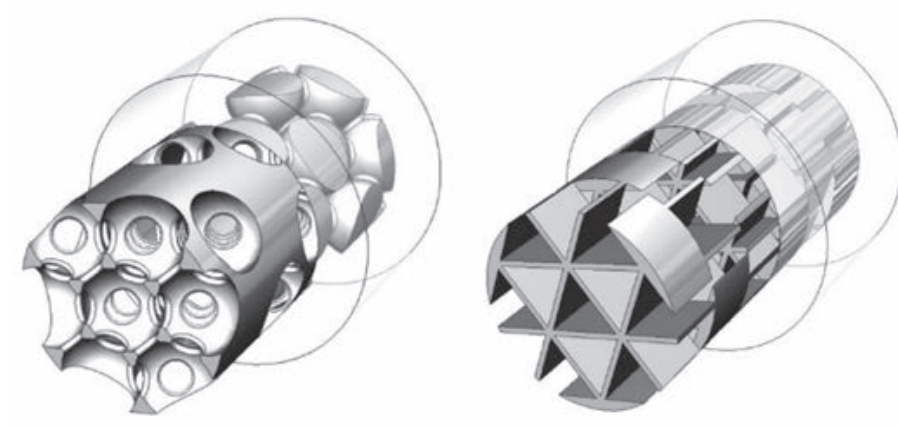

Fig. 1. View of the porous (left) and triangular (right) structured reactors.

Building on the knowledge obtained in the collaboration with EPFL (see above), the metal powders were coated with a primer layer, upon which the palladium could easily be deposited. ${ }^{[9 a, 11]}$ The primer precursor $\left(\mathrm{Al}_{2} \mathrm{O}_{3} / \mathrm{ZnO}\right.$ and $\left.\mathrm{CeO}_{2} / \mathrm{ZnO}\right)$ was then converted to the desired coating material by a subsequent thermal post-treatment. Optimization of primer and Pd-nanoparticleprocedures was carried out by testing parameters such as Pdloadings, the primer layer thickness and the thermal activation of the final catalyst. Prepared catalysts were tested in batch hydrogenation reactions and the catalysts were fully characterized by a number of different techniques.

The structured reactors were designed at ETH and manufactured by the laser sintering technique which allows for the production of 3D metal supports of nearly any shape. The novel designed structures consist of unit cells, which repeat periodically and allow easily for scaling in length and diameter of reactors. The $2^{\text {nd }}$ generation triangular structure (Fig. 1, right) was developed with the desire for an increased surface area, an improved dispersion quality and a reduced pressure drop compared to the porous structure (Fig. 1, left), whilst maintaining a similar porosity. The specific surface area of the triangular structure is more than doubled compared to the porous structure. Unlike monolith reactors with traversing channels, the triangular structure is made of radially translated layers of triangular channels which allows radial mixing and break-up of bubbles in between the layers. Up to $30-40 \%$ higher reaction rates in the whole range of the investigat-<smiles>C=C(C/C=C/C(C)=O)CCC=C(C)C</smiles>

Scheme 2. Sequential reductions of carbon-carbon double bonds using a SMF-catalyst.<smiles>C=C(C)CCC=C(C)C</smiles>

ed conditions was observed for the triangular structured reactor. After $270 \mathrm{~h}$ on stream, the TOF decreased by $13 \%$ compared to the original value; the original catalyst activity was re-established after a thermal treatment, showing the high stability of the catalytic coating of the structured reactors. ${ }^{[10 b]}$ The mini-plant setup was continuously improved and has now been transferred to the DSM laboratories (Fig. 2) and additional studies are on-going with further alkyne substrates.

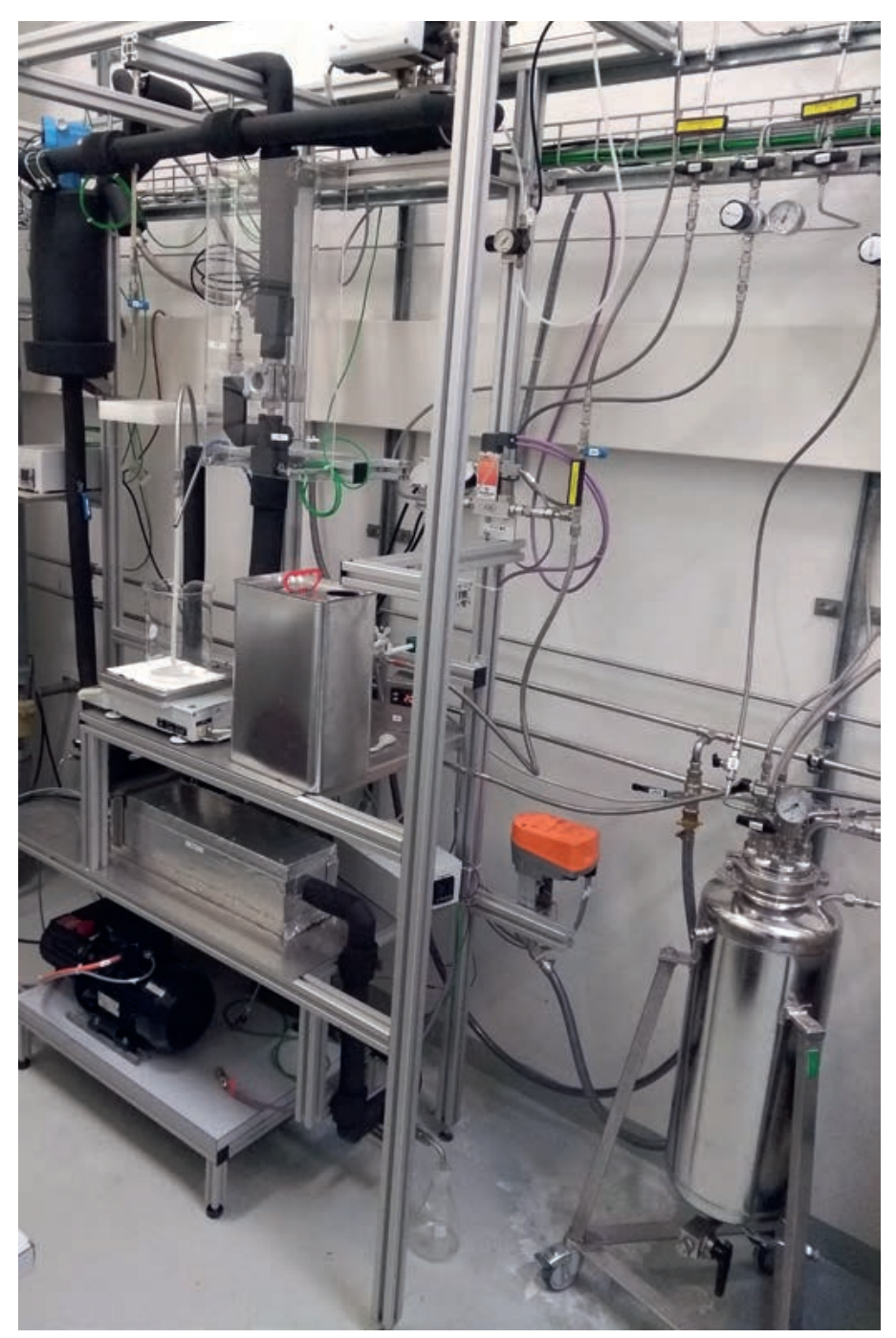

Fig. 2. The ETH-designed semi-hydrogenation mini-plant installed in a DSM laboratory. 


\section{Asymmetric Homogeneous Hydrogenation Reactions}

The term vitamin E covers a group of compounds exhibiting similar biological activity to $\alpha$-tocopherol. They vary in the different degree of methylation on the aromatic ring and contain either a saturated or a threefold unsaturated aliphatic side chain. From an industrial point of view, the most relevant product of this class is (all-rac)- $\alpha$-tocopherol, a lipid-soluble vitamin exerting an antioxidative effect that had a world-wide production volume of $\geq 75,000 \mathrm{t}$ in $2019 .{ }^{[12]}$ (all-rac)- $\alpha$-Tocopherol represents an equimolar mixture of all eight stereoisomers; however, the naturally occurring $(R, R, R)$-stereoisomer has the highest biological vitamin $\mathrm{E}$ activity. Therefore various investigations have been undertaken to achieve an industrially feasible synthesis of this compound. In particular, asymmetric hydrogenation was applied to introduce the stereogenic centres of the side chain by utilising the ruthenium-catalysed asymmetric hydrogenation of allylic alcohols. ${ }^{[13,14]}$ For example geraniol and nerol can be hydrogenated at only the allylic position at up to $\mathrm{S}: \mathrm{C} 50,000$ to give citronellol containing up to $99 \%$ of the (3R) isomer. ${ }^{[15]}$ Additionally, tetrahydrofarnesol 3 can be hydrogenated with S:C of up to 150,000 and selectivities of up to $98.6 \%$ at the newly-formed stereocentre of hexahydrofarnesol $(R, R)-4{ }^{[16]}$ The breakthrough development by Prof. A. Pfaltz of chiral iridium hydrogenation catalysts which do not require a neighbouring co-ordinating group for high selectivity ${ }^{[17]}$ was the starting point for a long-standing cooperation in this area. In an earlier collaboration, such complexes were used in the hydrogenation of $\gamma$-tocotrienyl acetate $\mathbf{5}$, reducing three double bonds in one step giving $>98 \%$ of the desired stereoisomer $(R, R, R)-6$ (Scheme $3)^{[18]}$ The same Ir-catalysts could also be successfully applied on farnesol and derivatives thereof. ${ }^{[19]}$ These catalysts are unique as they allow the hydrogenation of purely alkyl-substituted and un-activated carbon-carbon double bounds in high selectivity.

Although excellent results were achieved with both approaches, none of them is industrially feasible since the synthesis of the substrates applied in the asymmetric hydrogenation can be laborious and is not cost competitive. A great step towards an industrially feasible synthesis of the $(R, R, R)$-isomer was achieved in a further cooperation with the research group of Prof. A. Pfaltz at the University of Basel aiming for an asymmetric hydrogenation of $\gamma, \delta$-unsaturated ketones such as 7 . These compounds can be easily obtained via industrialized approaches to the vitamin E side chain. ${ }^{[20]}$ Since such substrates do not contain suitable coordination groups for $\mathrm{Ru}$ - or Rh-based catalysts, cationic iridium complexes (similar to those used for tocotrienol 5, Scheme 3) emerged as catalysts of choice. A screening of various catalysts revealed that the $o$-tolyl-derivatives delivered the highest selectivities in combination with a bulky substituent on the pyridine moiety. In particular, use of the anthracenyl substituted catalyst 9 resulted in 98.5\% of the desired isomer of ketone $\mathbf{8}$ (Scheme 4).

Screening of various solvents revealed that an even higher selectivity can be reached; trifluoroethanol and catalyst 9 resulted in the formation of up to $99.1 \%$ of the desired stereoisomer, an $e e>99 \%$ and a $d r$ of $124: 1$. This methodology can be applied to different substrates obtained by minor variations in the process (Scheme 5). Besides (5E,9E)-farnesyl acetone 7, different (E/Z)-
Scheme 3. Asymmetric hydrogenation approaches to the highly enantio-enriched tocopherol side chain.

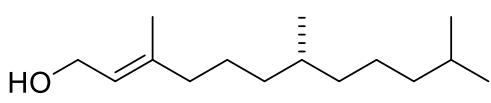

$(R)-3$

$\left((\mathrm{S})-\left(\mathrm{P}^{\wedge} \mathrm{P}\right) \mathrm{Ru}\left(\mathrm{O}_{2} \mathrm{CCF}_{3}\right)_{2}\right.$ $\mathrm{S}: \mathrm{C}$ up to 150,000 $\mathrm{H}_{2}$, MeOH<smiles>CC(C)CCC[C@H](C)CCC[C@H](C)CCO</smiles>
$(R, R)-4$

up to $99 \%$ conv., up to $98.6 \%$ ee (C3) $P^{\wedge} P=B I N A P$, TOIBINAP BIPHEMP, TOIBIPHEMP<smiles></smiles>

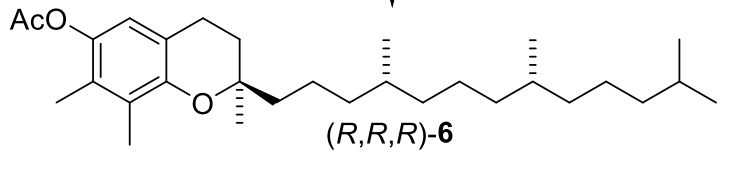

Scheme 4. Hydrogenation of $(5 E, 9 E)$-farnesylacetone 7 with different bicyclic pyridine-based catalysts. Complete conversion was obtained for all entries.

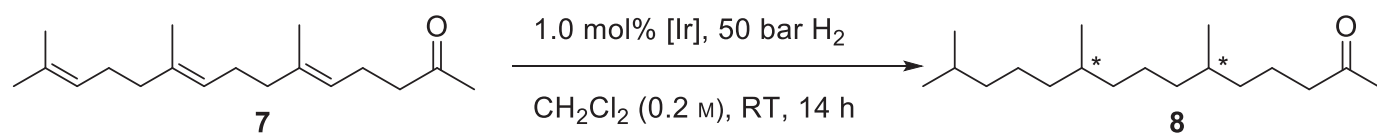

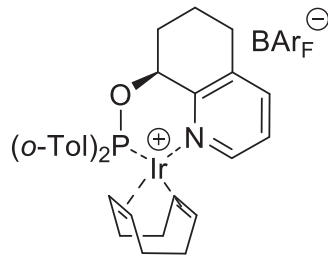

$46.8 \%(R, R)-8$

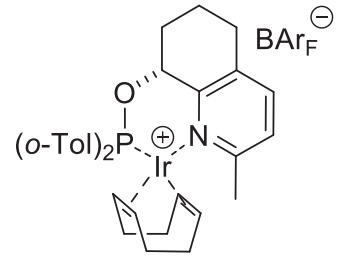

$88.3 \%(S, S)-8$

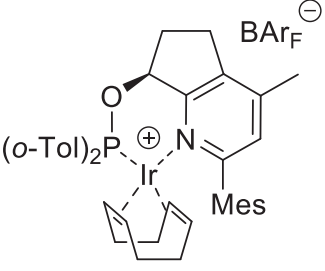

$96.1 \%(R, R)-8$

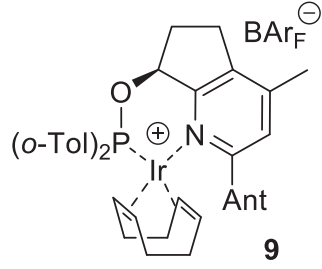

$98.5 \%(R, R)-8$ 
isomers, $\mathrm{C}_{13}$-analogues and substrates containing only prochiral double bonds can be envisioned. Especially the last ones are of interest as a cheaper heterogeneous catalyst can be used to hydrogenate the non-prochiral double bond. The hydrogenation of these substrates resulted in similar selectivity compared to $(5 E, 9 E)$ farnesyl acetone (7). If a double bond is present in $(Z)$ - instead of the $(E)$-configuration, the stereogenic centre of opposite configuration is formed. Consequently, the saturated $\mathrm{C}_{18}$-ketone $\mathbf{8}$ can be obtained not only in the desired $(R, R)$-form, but all four possible stereoisomers are accessible by the right choice of catalyst enantiomer and substrate.

The drawback of these catalysts is the requirement of the relatively high catalytic loading (minimum $0.1 \mathrm{~mol} \%$ ) for full conversion to the saturated ketones $\mathbf{8}$ and $\mathbf{1 0}$, meaning that such a process would not be commercially attractive. It was postulated that the ketone could be binding to the Ir-catalyst, leading to partial deactivation. Two ways were developed at DSM (a collaboration between the DSM sites in Switzerland and The Netherlands) to improve the turnover numbers of these hydrogenation reactions and therefore reduce the cost of the asymmetric hydrogenation. One was the use of a Lewis acid, such as an aluminium species. ${ }^{[21]}$ Even more successful was the transformation of the ketone into a ketal which resulted in a significantly higher catalyst productivity, maintaining the high selectivity (Scheme 6). For $(5 E, 9 E)$ farnesylactone $\mathbf{7}$ only $27 \%$ of the fully saturated product $\mathbf{8}$ was obtained with a molar substrate to catalyst loading of 1,000 (the remainder was partially hydrogenated intermediates), whereas the corresponding ketal gave $98 \%$ of the fully hydrogenated com- pound with excellent $(R, R)$ selectivity with half the amount of catalyst. Similar improvements in reactivity were obtained with the $\mathrm{C}_{13}$-ketone 12. ${ }^{[22]}$ For reasons of speed, DSM decided to scaleup the unmodified hydrogenation of the unsaturated ketones in a stepwise manner, producing more than $5 \mathrm{~kg}$ of the $\mathrm{C}_{13}$-ketone $\mathbf{1 0}$ and $1 \mathrm{~kg}$ of the $\mathrm{C}_{18}$-ketone $\mathbf{8}$ using catalyst $(S)-\mathbf{1 1}$, all in excellent yield and selectivity (Scheme 7).

\section{Acetophenone Synthesis by Solid-Acid Mediated Fries-Rearrangement}

Hydroxyarylketones find widespread industrial applications, in particular $o$-hydroxyacetophenones $\mathbf{1 4}$ are interesting synthons in organic chemistry, and play an important role as intermediates in the pharmaceutical, fragrance and fine chemical industries. A general route to the 4-chromanone framework can be utilized to access intermediates for the synthesis of vitamin E. ${ }^{23,24]}$ One of the most common methods of synthesising $o$-hydroxyacetophenones is utilising the Fries rearrangement of phenyl acetates $\mathbf{1 3}$ (Scheme 8). This process is conventionally homogeneously catalysed by strong Lewis or Brønsted acids. [25]

Various heterogeneous catalysts have been evaluated in order to replace the often corrosive and toxic reagents, such as $\mathrm{AlCl}_{3}, \mathrm{BF}_{3}$ or $\mathrm{HF}$, and to avoid the formation of chemically reactive waste streams in stoichiometric amounts. ${ }^{[26]}$ Limited information is, however, available on the substrate scope and, in particular, how different substitution patterns affect the yield and selectivity. We therefore started a systematic study on differently methyl-substituted phenyl acetates $13,{ }^{[27]}$ with special emphasis on the use of heterogeneous catalysts.

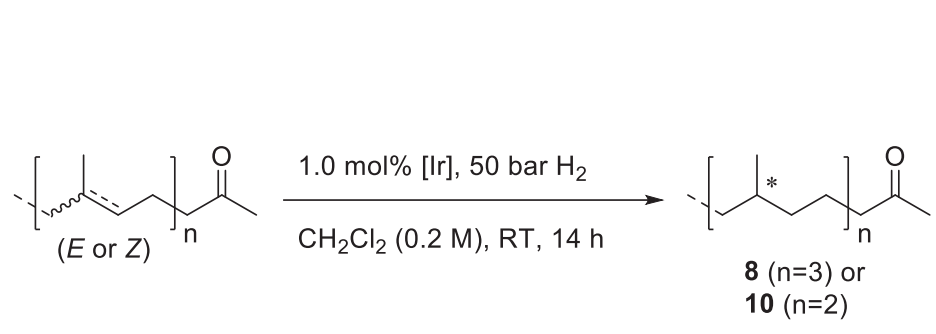

$+1$

converted to $96.6 \%(R, R)-8$

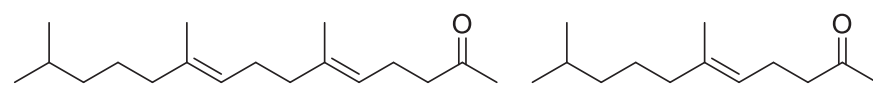

converted to $92.2 \%(R, R)-8$

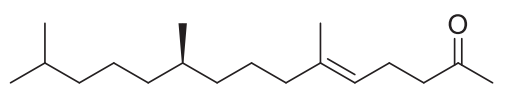

converted to $96.0 \%(R, R)-8$

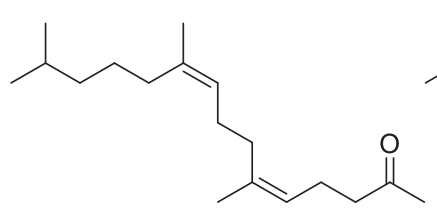

converted to $96.0 \%(S, S)-8$ converted to $98.6 \%(R)-10$
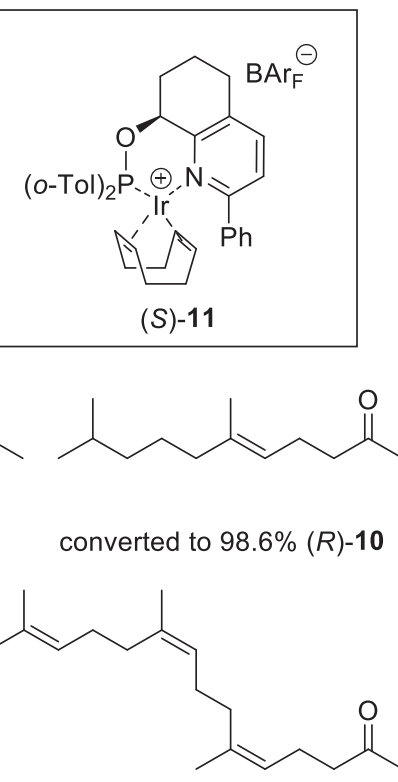

converted to $94.2 \%(S, S)-8$
Scheme 5. Hydrogenation of different substrates that can be applied as precursors for the vitamin E side chain. Complete conversion of the starting ketone was observed for all entries.

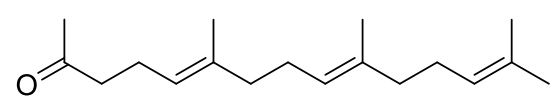

7, S:C 1,000 $27 \%$ yield of 8<smiles>CC(=O)CC/C=C(\C)CCCC(C)C</smiles>

12, S:C $10,0001 \%$ yield of 10<smiles>CC(C)=CCC/C(C)=C/CC/C(C)=C/CCC1(C)OCCO1</smiles>

S:C 2,000

$98 \%$ yield, $96 \%(R, R)$<smiles>CC(=CCCC1(C)OCCO1)CCCC(C)C</smiles>

Scheme 6. Asymmetric hydrogenation of ketals compared with the parent ketones. 
Scheme 7. The scale-up route to form the $(R, R)-\mathrm{C}_{18}$-ketone 8 .

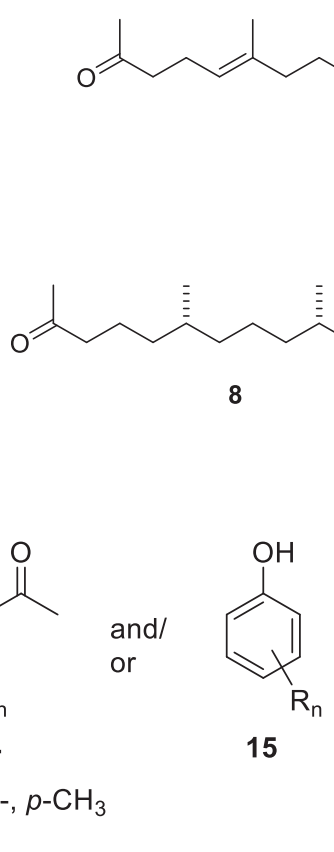

Scheme 8. Fries rearrangement of methyl-substituted phenyl acetates.

In collaboration with Prof. J. Pérez-Ramírez at ETH Zurich, a broad range of materials was screened and the most promising results were obtained with zeolite catalysts, in particular those containing large-pore sizes such as beta zeolites. This indicated a structure-activity relationship enabling efficient conversion of certain dimethylphenyl acetates. The channel dimensions and the pore-size strongly influence the framework-dependent rearrangement vs. competitive ester cleavage pathway yielding the phenols 15 as by-products. For example, using a beta zeolite, 3,4-dimethylphenyl acetate $\mathbf{1 6}$ gave a 77:23 mixture of acetophenone:phenol, whereas 3,5-dimethylphenyl acetate $\mathbf{1 7}$ gave solely the corresponding phenol, with $15 \%$ by-products (Scheme 9 ).

Computational visualization at DSM of the molecular structures of both the reactants (phenyl acetates) and the surface of the catalysts indicated that the catalytic reaction may take place at the pore-mouth, taking into account steric factors. Reasonable conversions and selectivities for acetophenones were obtained with phenyl acetates of low steric bulkiness, whereas higher sub-
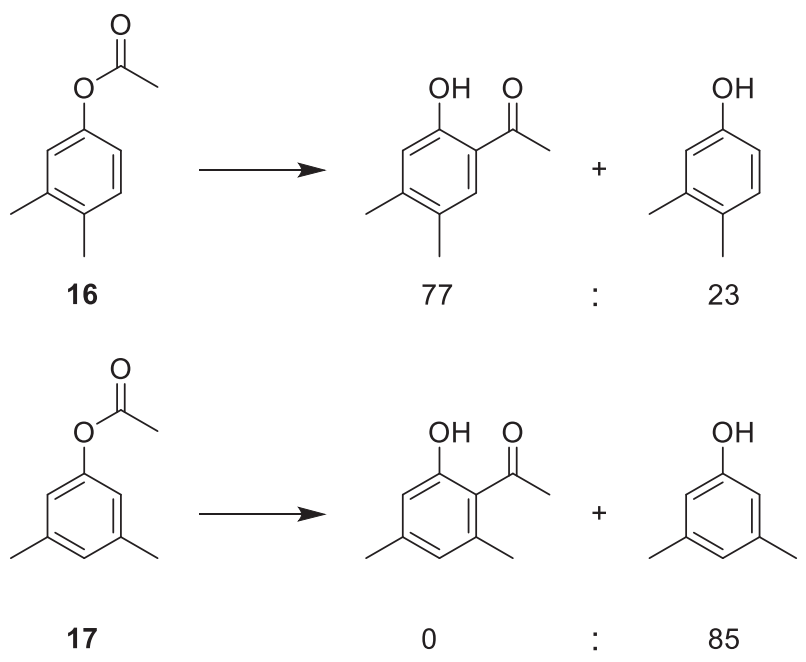

Scheme 9. Reaction of two differently substituted phenyl acetates catalysed by a beta zeolite. stituted phenyl acetates generally resulted in predominant acetate cleavage yielding phenols. In addition, the reaction of the phenols 15 with acetic anhydride to form the phenyl acetates $\mathbf{1 3}$ was also investigated. The catalysts used were characterized by a variety of techniques. Although deactivation of the catalyst was observed, it was found that the performance could be fully restored by an oxidative thermal treatment. The results obtained in the collaboration allowed a deeper understanding of which hydroxyacetophenones could be synthesized by a zeolite-catalysed Fries rearrangement, thus providing valuable input to $\mathrm{R} \& \mathrm{D}$ projects at DSM.

\section{Selective Mono-Acetylation of a Vitamin A Intermediate}

Vitamin A is important for the vision process, the immune system, and for healthy skin and is generally produced as the more stable acetate derivative. Several chemical routes to vitamin A acetate have been industrialized; in the DSM process, the intermediate diol (18) is acetylated on the primary alcohol to form 19, followed by elimination and isomerization to afford (all- $E$ )-vitamin A acetate 21 (Scheme 10). ${ }^{[28]}$ However, a significant amount of the diacetate $\mathbf{2 0}$ is also formed. Since higher yields can be obtained in the following steps if the pure mono-acetate is used, DSM was interested in exploring if a selective acetylation was possible using heterogeneous catalysts. ${ }^{[29]}$

The selective acylation was investigated in a research project with Prof. J. Pérez-Ramírez's group at ETH Zurich. ${ }^{[30]}$ The homogeneous catalysed acetylation was first studied in more detail. When pyridine was applied as a basic catalyst, the mono-acetylated product (19) and the bis-acetylated product (20) formed in a ratio of about $3: 1$; the selectivity of acetylation could not be significantly influenced. The use of a heterogeneous catalyst could open new pathways that might achieve a higher mono-acetylation selectivity and it additionally would simplify the removal of the catalyst and its reuse. The use of hydrotalcites (layered double hydroxides) was chosen since it is possible to tune the catalyst by a number of variables in its synthesis. Medium and strong basic sites were varied by changing the $\mathrm{Al}-\mathrm{Mg}$ ratio of the hydrotalcite; after preparation, the catalysts were thermally treated at temperatures ranging from 400 to $1,000{ }^{\circ} \mathrm{C}$ forming mixed metal oxides. The mesoporous structure of these compounds allows the bulky vitamin A intermediates to access the active sites of the catalyst. The catalysts were extensively characterized and activation at $700{ }^{\circ} \mathrm{C}$ resulted in maximum surface area of $161 \mathrm{~m}^{2} / \mathrm{g}$. At higher temperatures the formation of spinel type structures was more favoured (with decreasing surface area).

The catalysts were applied in the acetylation of $\mathbf{1 8}$ under similar conditions as the pyridine catalysed acetylation. Non-thermally treated hydrotalcites showed a very high selectivity (nearly 100\%) towards mono-acetylation under mild conditions, albeit with low conversions $(<20 \%)$. The highest conversion $(45 \%)$ was obtained with the hydrotalcite treated at $700{ }^{\circ} \mathrm{C}$; the selectivity remained very high with only minor amounts of bis-acetylated product $\mathbf{2 0}$ being formed. The conversion could be improved by increasing the reaction temperature, with a small drop in selectivity. The var- 


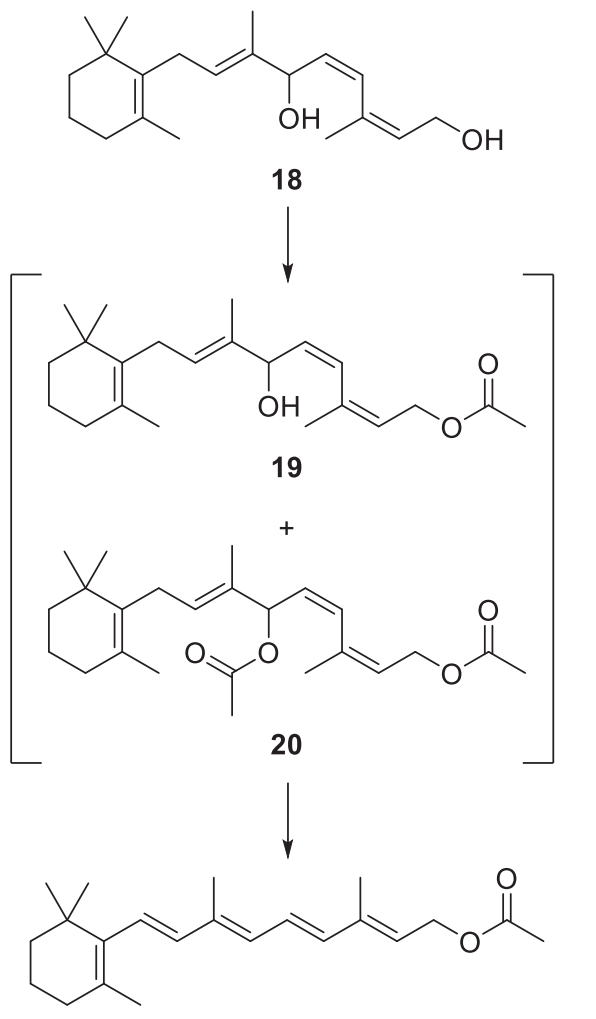

(all-E)-vitamin $\mathrm{A}$ acetate $\mathbf{2 1}$

Scheme 10. Acetylation of an intermediate to vitamin A acetate.

iation of the $\mathrm{Al}-\mathrm{Mg}$ ratio in the range from 1:1 to $4: 1$ also had an influence on both the activity and selectivity of the catalysts.

One advantage of using a heterogeneous catalyst is that it can be reused and this was studied in batch experiments. Over five runs, the yield of the mono-acetylated product 19 decreased slightly. XRD measurements showed that the structure of the mixed oxides changed slightly and organic deposits on the catalyst could be observed which were also a factor in the decreasing activity. However, the activity could be returned to almost the initial value by oxidative thermal treatment, removal of the organic deposits and restoring the initial mixed oxide structure. Overall it was demonstrated that a highly selective mono-acetylation could be achieved using heterogeneous catalysts derived from earth-abundant and non-toxic elements under mild reaction conditions.

\section{Oxidation Reactions}

One key building block in the synthesis of vitamin E is 2,3,5-trimethylhydroquinone (TMHQ 25). The compound is typically produced by oxidation of 2,3,6-trimethylphenol (2,3,6-TMP 22) to 2,3,5-trimethylquinone (TMQ 24), followed by hydrogenation to TMHQ 25 (Scheme 11). ${ }^{[12]}$ However, most industrial processes currently require high loadings of environmentally problematic copper catalysts for the oxidation of phenols. ${ }^{[31,32]}$

DSM was interested in developing a safer, more environmentally friendly and cheaper process to TMQ 24. One possibility would be the application of the catalytic photo-oxidation of phenols in benign solvents in continuous flow. As there was only limited experience of this technology in-house, we started a collaboration with the group of Prof. C. Sparr at the University of Basel. This is a good example of how DSM tackles such a problem in an early research phase.

DFT calculations were carried out at DSM to assess the reactivity of 2,3,5-TMP 23 and 2,3,6-TMP 22 towards singlet oxygen. The computed transition state energies indicated the kinetic feasibility of both reactions. The free energy barrier from 2,3,5-TMP compared to $2,3,6-\mathrm{TMP}$ is about $2.0 \mathrm{kJmol}^{-1}$ lower, whereas the<smiles>CCc1ccc(C)c(O)c1CC</smiles>

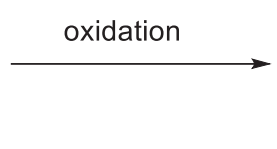<smiles>CC1=CC(=O)C(C)=C(C)C1=O</smiles><smiles>Cc1cc(C)c(C)c(O)c1</smiles>

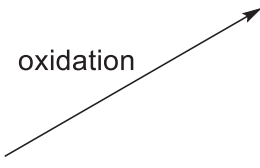

TMQ, 24 reduction<smiles>CCc1c(O)cc(C)c(O)c1C</smiles>

TMHQ, 25

Scheme 11. Synthesis of TMHQ 25 starting from 2,3,5-TMP 23 and 2,3,6-TMP 22.

conformation of 2,3,6-TMP with the lowest energy possesses a slightly higher intrinsic free energy than 2,3,5-TMP in the ground state.

A photosensitizer screening was carried out at the University of Basel to confirm the DTF predictions and two starting phenol substrates were investigated. The most suitable photocatalyst for the oxidation of both substrates was methylene blue, producing good yields of 2,3,5-trimethylquinone $\mathbf{2 4}$ starting from both phenols. ${ }^{[33]}$ This was a surprising and interesting result since in the copper-catalysed process, significantly lower yields are obtained using 2,3,5-TMP 23 compared to 2,3,6-TMP 22.

The reaction conditions were further optimized and a photoreactor was designed and tested. The reactor consisted of 12 hyper red LEDs, an integrated CPU cooling system and the reaction mixture flowed through perfluoroalkoxy alkane (PFA) tubing wrapped around the light source (Fig. 3). 2,3,5-TMP was almost quantitatively converted in a 4:1 MeOH/H $\mathrm{H}_{2} \mathrm{O}$ solvent mixture with 5 bar $\mathrm{O}_{2}$ or 10 bar air and 0.9 mol\% methylene blue to give a $96 \%$ yield of TMQ. A wide range of phenolic substrates could also be oxidized to their corresponding quinones, including 2-methylnaphthol to menadione 26 (vitamin $\mathrm{K}_{3}$ ), (Scheme 12). However, unsubstituted phenols and electron-deficient phenols remained unreacted.

Overall, a mild and sustainable synthesis of quinones and naphthoquinones was enabled by using a LED light source in a continuous-flow photoreactor using unproblematic solvents and short reaction times. Based on the successful results, the flow reactor developed in Basel has been installed in DSM's laboratories and further oxidation reactions are currently under investigation.<smiles>[R]c1ccc2c(c1O)CCCC2</smiles><smiles>COC1=CC(=O)C(C)=CC1=O</smiles><smiles>CC1=CC(=O)c2ccccc2C1=O</smiles><smiles>O=C1C=CC(=O)c2c(O)cccc21</smiles><smiles>O=C1C=CC(=O)c2ncccc21</smiles>

Scheme 12. Photochemical flow oxidation of phenols and naphthols to quinones and 1,4-naphthoquinones. 


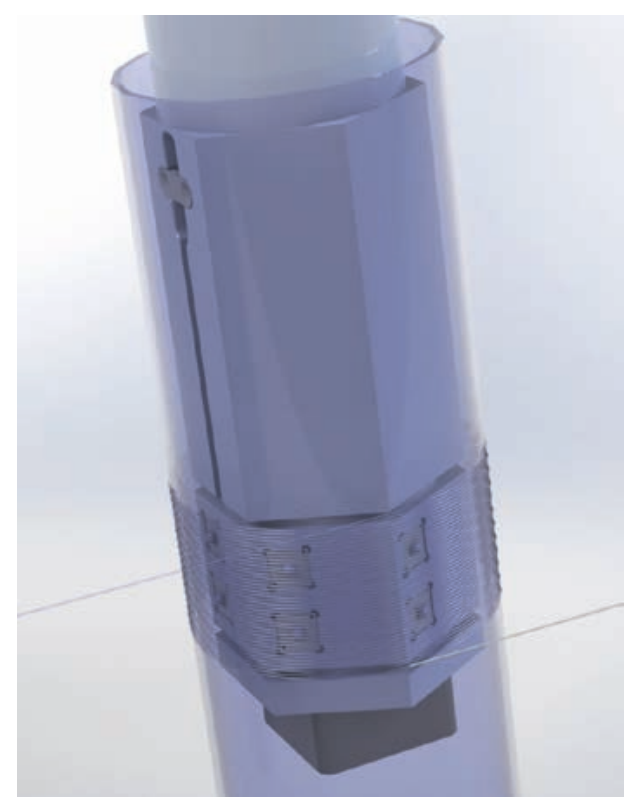

Fig. 3. Photoreactor designed and used for flow oxidation experiments. The light shielding aluminium foil is omitted for clarity. (Adapted from ref. [33], (C) 2021 Wiley-VCH GmbH)

\section{7. (R)-Pantolactone (for Pantothenic Acid and Panthenol)}

Pantothenic acid $28(\mathrm{R}=\mathrm{H})$, is also known as vitamin $\mathrm{B}_{5}$ and is important for the metabolism of carbohydrates, fats and proteins and also for the maintenance and repair of cells. It is predominately sold as its calcium salt for human and animal nutrition, and food and pharmaceutical use. The related D-panthenol 29 is used in pharmaceuticals, cosmetics and shampoos. The synthesis of both compounds use the same key intermediate, $(R)$-pantolactone $(R)$ 27 (Scheme 13). Currently all manufacturing routes start from the rac-pantolactone and perform a resolution. ${ }^{[34]}$ We were interested in developing an improved and more sustainable asymmetric synthesis of $(R)$-pantolactone 27. Different approaches were investigated at DSM, InnoSyn in the Netherlands and at the University of Basel.

An elegant route, using the existing rac-pantolactone ( $r a c-27)$ would be a dynamic kinetic resolution, where the desired $(R)$ isomer would be acylated to produce $(R)-\mathbf{3 0}$ and the undesired $(S)$ 27 would be racemized in situ and then further converted to $(R)$ 30. This has the potential for a ' $100 \%$ yield' process and uses a very cheap starting material (Scheme 14). A suitable racemization protocol was developed at DSM using the Shvo-catalyst ${ }^{[35]}$ and a $(R)$-selective lipase was developed by InnoSyn and colleagues at DSM Delft (NL) by performing docking studies and site-selec- tive mutagenesis starting from the well-known Candida antartica lipase B (CalB) which showed low $(R)$-selectivity. ${ }^{[36]}$ Although successful, the racemization required elevated temperatures and the lipase reaction was not selective enough, therefore this approach was put on hold.

An alternative concept is the reduction of ketopantolactone $\mathbf{3 1}$. The asymmetric hydrogenation has been known for many years, based on work developed at Roche/DSM and elsewhere. ${ }^{[37]} \mathrm{We}$ investigated a number of modern asymmetric hydrogenation catalysts, but unfortunately could not find one with suitable reactivity and selectivity. Therefore we investigated the use of an enzymatic reduction, also in collaboration with InnoSyn (Scheme 15). One problem that was encountered was a significant, less selective,

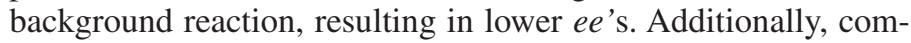
peting hydrolytic ring opening of the starting lactone 31 meant that the reduction could be occurring on the lactone, or the corresponding hydroxy acid, or both, potentially with different selectivities. A good protocol was developed with a keto-reductase at $\mathrm{pH} 5.5$ resulting in $e e$ 's of $>95 \%$, but this required the use of the expensive NADPH as co-factor. ${ }^{[38]}$ Slightly lower yields, but excellent selectivity were obtained with alternative enzymes.

Although successful, the synthesis of the starting ketopantolactone $\mathbf{3 1}$ could not be carried out in a cost-effective manner, so an alternative approach was investigated in a collaboration with the group of Prof. C. Sparr at the University of Basel. This involved an asymmetric organocatalysed condensation of isobutyraldehyde with a glyoxalate to give intermediate 32, which would then undergo aldehyde reduction and ring closure to give $(R)$ pantolactone 27 (Scheme 16) in a sequential catalytic approach. Initial results showed that a hybrid (33) between D-proline and Noyori's TsDPEN ligand for catalytic transfer hydrogenation was successful for the aldol condensation and, after addition of $\left[\mathrm{RuCl}_{2}(\mathrm{p} \text {-cymene })\right]_{2}$ and sodium formate, resulted in reduction and lactonization producing $(R)-\mathbf{2 7}$ with $99 \%$ conversion and an er of $82: 18 .{ }^{[39]}$ The stereoselectivity was controlled by the chiral proline unit, since the corresponding ligand without the two phenyl groups (34) gave similar selectivity and even a proline-amino alcohol derived ligand $\mathbf{3 5}$ was the most selective. Performing the

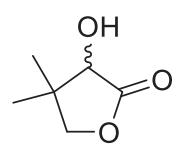

rac-27

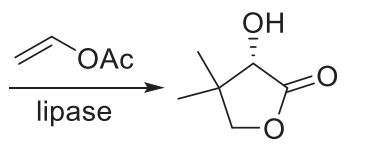

(S)-27

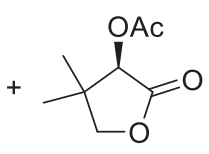

$(R)-30$
Scheme 14. Dynamic kinetic resolution (DKR) approach to $(R)$ pantolactone acetate.

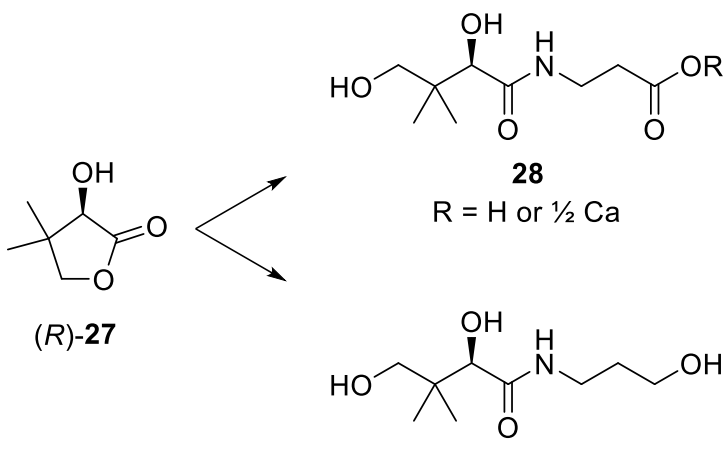

29<smiles>CC1(C)COC(=O)C1=O</smiles>

31

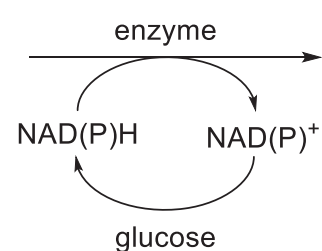

dehydrogenase

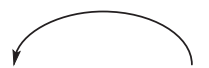

gluconic acid glucose<smiles>CC1(C)COC(=O)[C@H]1O</smiles>

$(R)-27$

Scheme 13. Preparation of calcium pantothenate and panthenol from $(R)$-pantolactone. 


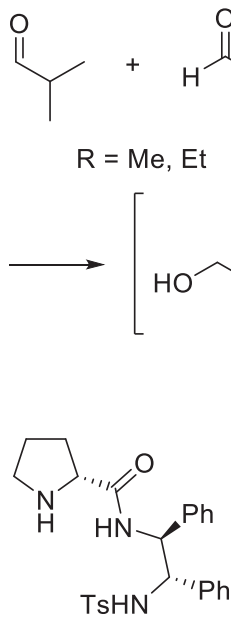

33

$99 \%$ conv. $82: 18$ er

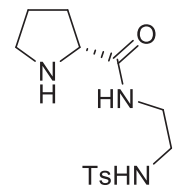

34

$99 \%$ conv. 85:15 er

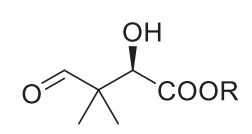

32<smiles>CC1(C)COC(=O)C1O</smiles>

$(R)-27$

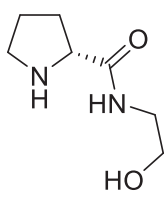

35

$99 \%$ conv.

$86: 14$ er
Scheme 16. Catalyst repurposing sequential catalysis approach to $(R)$-pantolactone.

transfer hydrogenation with $\left[\mathrm{Ir}\left(\mathrm{Cp}^{*}\right) \mathrm{Cl}_{2}\right]_{2}$ was even more successful resulting in an isolated yield of $84 \%$ with an er of 86:14 using just $0.1 \mathrm{~mol} \%$ of the iridium complex.

Overall, the combination of in-house knowledge and investigations and collaborations with experts in particular fields, resulted in three new approaches to the important intermediate $(R)$ pantolactone.

\section{Vitamin E: From Bio-organic Chemistry to Catalytic Synthesis Methodology}

The biocatalytic formation of $(R, R, R)$ - $\alpha$-tocopherol $(R R R-37)$ was the starting point for a long-standing collaboration with the group of Prof. W.-D. Woggon at the University of Zurich and later at the University of Basel. The initial identification of the enzyme tocopherol cyclase was followed by studies of the reaction mechanism of the stereospecific chromanol ring formation and on substrate specificity, ${ }^{[40]}$ as well as work on catalytic antibodies. ${ }^{[41]}$ The biomimetic chromanol cyclization reaction of $\mathbf{3 6}$ (Scheme 17), ${ }^{[42]}$ and of a structurally related substrate, ${ }^{[43]}$ may be mentioned as a link between the biosynthesis and the organo/chemocatalytic synthesis of $(R, R, R)-37$. Several novel approaches for the highly stereoselective generation of the $\mathrm{C}(2)$ stereogenic centre were described ${ }^{[44]}$ and comparatively reviewed. ${ }^{[45]}$

The methodology developed could also be used to gain additional knowledge about biologically interesting actions of vitamin E components and analogues. The asymmetric synthesis of nor- $\alpha$ tocopherol (in which the methyl group at position $\mathrm{C} 2$ is replaced by a hydrogen atom) enabled the discovery of biological activities beyond the established antioxidant properties. ${ }^{[46]}$ The formation of high molecular weight oligomers of $\alpha$-tocopherol transfer protein was detected in a study led by the Stocker group at the University of Bern. ${ }^{[47]}$ A study of the mobility of various vitamin E components in bio-membrane models by fluorescence quenching experiments was initiated by the Nau group at the University of Basel, and completed at the Jacobs University Bremen (Germany). ${ }^{[48]}$

In addition to collaborative projects with Swiss academic institutions, DSM has hosted a number of students from Switzerland and neighbouring countries to carry research projects as part of diploma, bachelor and master theses. In particular there are long-standing relationships with the Universities of Applied Sciences e.g., the School of Life Sciences at Muttenz/ Basel and the Zurich University of Applied Sciences Winterthur, ${ }^{[49]}$ mostly related to research in the area of vitamin E, and (+)-biotin.
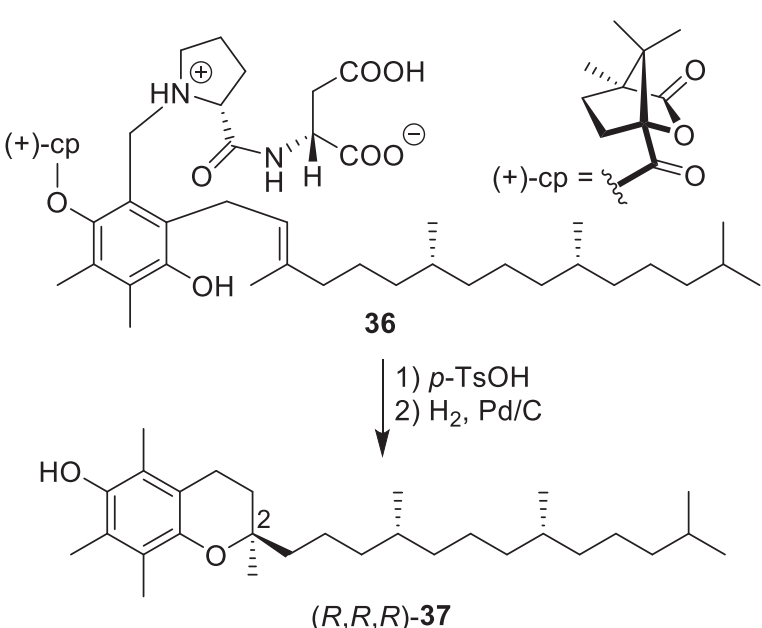

Scheme 17. Biomimetic stereoselective chromanol ring formation.

In many of the examples mentioned above, some points of such collaborations should be mentioned going beyond the purely financial support of the industrial partner. For example, the supply of samples as starting material or as reference materials, which are not commercially available, i.e. stereoisomers, isotopically labelled compounds, or structurally related substances often not only help but even initiate certain aspects in an investigation. In addition, expert knowledge and advice on specific compound-classes has been provided that is not necessarily available in the open literature. Furthermore, support to academic partners can be performing specialized analytics and/or providing methods. Whilst there is no direct monetary value of this support, it may be invaluable for the success of a research project.

\section{Conclusions and Final Words}

DSM has collaborated with a number of Swiss academics and institutions on a wide variety of topics. All the projects have been successful in one way or another; either by defining the scope and limitations of a particular transformation and/or catalyst, or developing new chemistry and synthetic routes to nutritional ingredients. We have seen examples above of new reactor concepts being developed and then brought in-house at DSM (e.g. continuous semi-hydrogenation and flow photochemistry), heterogeneous catalysts for selective reactions (acetylation and Fries rearrangement), new catalytic concepts (such as the catalyst repurposing sequential catalysis) and the development of processes to produce multi-kilograms of key intermediates (asymmetric hydrogenation). In addition to the valuable collaborations with Swiss academic institutions, DSM honoured to sponsor the Best Poster Presentation Awards at the SCS Fall Meeting providing to the students cash contributions, travel vouchers to attend international conferences, and invitations to present the research in an issue of Chimia. Overall, it has been an exceeding fruitful past decade and we look forward with great interest and expectation to the decades to come.

\section{Acknowledgements}

We are deeply indebted to all our collaborators in Swiss academia who have worked with us on interesting and challenging projects, both described here and in earlier cooperations not mentioned. The large number of people involved means we cannot individually thank them here, but they are referred to in the references. In addition we thank numerous DSM colleagues for their scientific discussions, ideas, comments and support (including analytical) of all our R\&D projects. The collaborations have been supported by funding from DSM and in some cases also with grants from the Swiss Commission for Technology and Innovation (CTI). 
[1] W. Bonrath, J. Medlock, J. Schütz, B. Wüstenberg, T. Netscher, 'Hydrogenation in the Vitamins and Fine Chemicals Industry - An Overview', in 'Hydrogenation', Chapter 3, Ed. I. Karamé, InTech, Rijeka, Croatia, 2012, 69.

[2] H. Lindlar, Helv. Chim. Acta 1952, 35, 446 , https://doi.org/10.1002/hlca.19520350205.

[3] W. Bonrath, B. Ondruschka, C. Schmöger, A. Stolle, WO 2010020671, 2010.

[4] a) Z. Wu, N. Cherkasov, G. Cravotto, E. Borretto, A. O. Ibhadon, J. Medlock, W. Bonrath, ChemCatChem 2015, 7, 952, https://doi.org/10.1002/cctc.201402999; b) E. Calcio Gaudino, M. Manzoli, D. Carnaroglio, Z. Wu, G. Grillo, L. Rotolo, J. Medlock, W. Bonrath, G. Cravotto, RSC Adv. 2018, 8, 7029, https://doi.org/10.1039/C8RA00331A

[5] U. Krtschil, P. Löb, C. Schütt, R. Zapf, R. James, W. Bonrath, J. Medlock, Chem. Eng. Tech. 2019, 42, 407, https://doi.org/10.1002/ceat.201800541.

[6] A. Bruehwiler, N. Semagina, M. Grasemann, A. Renken, L. Kiwi-Minsker, A Saaler, H. Lehmann, W. Bonrath, F. Roessler, Ind. Eng. Chem. Res. 2008, 47, 6862, https://doi.org/10.1021/ie800070w.

[7] a) W. Bonrath, T. Müller, L. Kiwi-Minsker, A. Renken, I. Iouranov, WO 2011092280, 2011; b) W. Bonrath, L. Kiwi-Minsker, I. Iouranov, WO 2012001166, 2012; c) W. Bonrath, L. Kiwi-Minsker, I. Iouranov, WO 2013060821,2013

[8] W. Bonrath, L. Kiwi-Minsker, I. Iouranov, L. Cardenas, A. L. Dessimoz, WO 2014057075, 2014

[9] a) Y. Elias, P. Rudolf von Rohr, W. Bonrath, J. Medlock, A. Buss, Chem. Eng. Process. - Process Intensif. 2015, 95, 175, https://doi.org/10.1016/j.cep.2015.05.012; b) R. Häfeli, O. Rüegg, M. Altheimer, P. Rudolf von Rohr, Chem. Eng. Sci. 2016, 143, 86, https://doi.org/10.1016/j.ces.2015.12.022; c) C. Hutter, R. R. Von, F. Mascarello, D. Ruppen, EP2260937, 2010.

[10] a) S. Vernuccio, R. Goy, P. Rudolf von Rohr, J. Medlock, W. Bonrath, React. Chem. Eng. 2016, 1, 445, https://doi.org/10.1039/ C6RE00093B; b) S. Vernuccio, D. Dempfle, R. Goy, J. Medlock, P. Rudolf von Rohr, Chem. Eng. Process. - Process Intensif. 2018, 126, 74, https://doi.org/10.1016/j.cep.2018.02.005; c) S. Vernuccio, R. Goy, A. Meier, P. Rudolf von Rohr, J. Medlock, Chem. Eng. J. 2017, 316, 121, https://doi. org/10.1016/j.cej.2017.01.068.

[11] A. Montebelli, C. G. Visconti, G. Groppi, E. Tronconi, C. Cristiani, C. Ferreira, S. Kohler, Catal. Sci. Technol. 2014, 4, 2846, https://doi.org/10.1039/C4CY00179F.

[12] W. Bonrath, A. Wyss, G. Litta, K.-U. Baldenius, L. von dem BusscheHünnefeld, E. Hilgemann, P. Hoppe, R. Stürmer, T. Netscher, 'Vitamins, 4. Vitamin E (Tocopherols, Tocotrienols)' in 'Ullmann's Encyclopedia of Industrial Chemistry', Online ed. Weinheim, Germany, Wiley-VCH Verlag GmbH \& Co, 2021

[13] H. Kumobayashi, Recl. Trav. Chim. Pays-Bas 1996, 115, 201, https://doi.org/10.1002/recl.19961150403.

[14] S. Akutagawa, Appl. Catal. A: Gen. 1995, 128, 171, https://doi.org/10.1016/0926-860X(95)00097-6.

[15] H. Takaya, T. Ohta, N. Sayo, H. Kumobayashi, S. Akutagawa, S. Inoue, I. Kasahara, R. Noyori, J. Am. Chem. Soc. 1987, 109, 1596, https://doi.org/10.1021/ja00239a065.

[16] T. Netscher, M. Scalone, R. Schmid, 'Enantioselective Hydrogenation: Towards a Large-Scale Total Synthesis of $(R, R, R)-\alpha$-Tocopherol', in 'Asymmetric Catalysis on an Industrial Scale: Challenges, Approaches and Solutions', Eds. H. U. Blaser, E. Schmidt, Wiley-VCH, 2004, 71

[17] D. H. Woodmansee, A. Pfaltz, Chem. Commun. 2011, 47, 7912, https://doi.org/10.1039/C1CC11430A.

[18] S. Bell, B. Wüstenberg, S. Kaiser, F. Menges, T. Netscher, A. Pfaltz, Science 2006, 311, 642, https://doi.org/10.1126/science.1121977.

[19] A. Wang, B. Wüstenberg, A. Pfaltz, Angew. Chem. Int. Ed. 2008, 47, 2298, https://doi.org/10.1002/anie.200705521.

[20] M. Eggersdorfer, D. Laudert, U. Létinois, T. McClymont, J. Medlock, T. Netscher, W. Bonrath, Angew. Chem. Int. Ed. 2012, 51, 12960, https://doi.org/10.1002/anie.201205886.

[21] J. A. Medlock, G. K. M. Verzijl, E. G. Ijpeij, A. H. M. de Vries, WO 2014097170 , 2014

[22] W. Bonrath, T. Netscher, J. A. Medlock, G. K. M. Verzijl, A. H. M. de Vries WO 2014096096, 2014

[23] H.-J. Kabbe, A. Widdig, Angew. Chem. Int. Ed. Engl. 1982, 21, 247, https://doi.org/10.1002/anie.198202471

[24] T. Netscher, Chimia 2018, 72, 485, https://doi.org/10.2533/chimia.2018.485.

[25] R. Martin, Org. Prep. Proc. Int. 1992, 24, 369, https://doi.org/10.1080/00304949209356226.

[26] W. Hölderich, M. Hesse, F. Näumann, Angew. Chem. Int. Ed. Engl. 1988, 27, 226, https://doi.org/10.1002/anie.198802261.

[27] R. Lin, S. Mitchell, T. Netscher, J. Medlock, R. T. Stemmler, W. Bonrath, U. Létinois, J. Pérez-Ramírez, Cat. Sci. Technol. 2020, 10, 4282, https://doi.org/10.1039/D0CY00590H

[28] B. Wüstenberg, M. A. Müller, J. Schütz, A. Wyss, G. Schiefer, G. Litta, M. John, W. Hähnlein, 'Vitamins, 2. Vitamin A (Retinoids)', in 'Ullmann's Encyclopedia of Industrial Chemistry'. Online ed. Weinheim, Germany, Wiley-VCH Verlag $\mathrm{GmbH} \& \mathrm{Co}, \mathbf{2 0 2 0}$
[29] a) B. Orsat, B. Wirz, S. Bischof, Chimia 1999, 53, 579; b) W. Bonrath, R. Karge, T. Netscher, J. Mol. Catal. B: Enzym. 2002, 19-20, 67, https://doi.org/10.1016/S1381-1177(02)00152-2.

[30] F. J. A. G. Coumans, S. Mitchell, J. Schütz, J. Medlock, J. Pérez-Ramírez, ACS Omega 2018, 3, 15293, https://doi.org/10.1021/acsomega.8b02234.

[31] P. Gamez, J. Schütz, T. Netscher, 'Phenol Oxidations', in 'Liquid Phase Aerobic Oxidation Catalysis: Industrial Applications and Academic Perspectives', Eds. S. S. Stahl, P. L. Alsters, Wiley-VCH Verlag, 2016, 97-111.

[32] K. V. N. Esguerra, Y. Fall, L. Petitjean, J.-P. Lumb, J. Am. Chem. Soc. 2014, 136, 7662, https://doi.org/10.1021/ja501789x.

[33] J. Wellauer, D. Miladinov, T. Buchholz, J. Schütz, R. T. Stemmler, J. A. Medlock, W. Bonrath, C. Sparr, Chem. Eur. J. 2021, 27, 9748 , https://doi.org/10.1002/chem.202101313.

[34] M.-A. Müller, J. Medlock, Z. Prágai, I. Warnke, G. Litta, A. Kleefeldt, K. Kaiser, B. De Potzolli, 'Vitamins, 9. Vitamin B5' in 'Ullmann's Encyclopedia of Industrial Chemistry', Online ed. Weinheim, Germany, Wiley-VCH Verlag $\mathrm{GmbH} \& \mathrm{Co}, 2019$

[35] W. Bonrath, J. Medlock, J. Voldrich, CN 112047906, 2020.

[36] R. M. De Jong, J. A. Medlock, M. Mueller, D. M. C. Callant, L. A. L. Vermote, M. Schuermann, EP 3748008, 2020.

[37] a) E. A. Broger, Y. Crameri, EP 0158875, 1985; b) E. A. Broger, Y. Crameri, EP 0218970, 1987

[38] W. Bonrath, J. A. Medlock, M. Mueller, L. A. L. Vermote, Patent application filed.

[39] F. Bourgeois, J. A. Medlock, W. Bonrath, C. Sparr, Org. Lett. 2020, 22, 110 , https://doi.org/10.1021/acs.orglett.9b04033.

[40] a) A. Stocker, W.-D. Woggon, A. Rüttimann, Helv. Chim. Acta 1993 76, 1729, https://doi.org/10.1002/hlca.19930760429; b) A. Stocker, T. Netscher, A. Rüttimann, R. K. Müller, H. Schneider, L. J. Todaro, G. Derungs, W.-D. Woggon, Helv. Chim. Acta 1994, 77, 1721, https://doi.org/10.1002/hlca.19940770705; c) A. Stocker, H. Fretz, H Frick, A. Rüttimann, W.-D. Woggon, Bioorg. Med. Chem. 1996, 4, 1129, https://doi.org/10.1016/0968-0896(96)00125-3; d) W.-D. Woggon, Chimia 1999, 53, 234.

[41] a) R. Manetsch, L. Zheng, M. T. Reymond, W.-D. Woggon, J.-L. Reymond, Chem. Eur. J. 2004, 10, 2487, https://doi.org/10.1002/chem.200305629; b) L. Zheng, R. Manetsch, W.-D. Woggon, U. Baumann, J.-L. Reymond, Bioorg. Med. Chem. 2005, 13, 1021, https://doi.org/10.1016/j.bmc.2004.11.041.

[42] C. Grütter, E. Alonso, A. Chougnet, W.-D. Woggon, Angew. Chem. Int. Ed. 2006, 45, 1126, https://doi.org/10.1002/anie.200503123.

[43] J. Chapelat, A. Chougnet, W.-D. Woggon, Eur. J. Org. Chem. 2009, 2069.

[44] a)J.Chapelat,A.Buss,A.Chougnet,W.-D.Woggon,Org.Lett.2008,10,5123,https:// doi.org/10.1002/ejoc.200900019; b) U. Hengartner, A. Chougnet, K. Liu, W.-D. Woggon, Chem. Eur. J. 2010, 16, 1306, https://doi.org/10.1002/chem.200902754 c) K. Liu, A. Chougnet, W.-D. Woggon, Angew. Chem. Int. Ed. 2008, 47, 5827, https://doi.org/10.1002/anie.200801765; d) K. Liu, W.-D. Woggon, Eur. J. Org Chem. 2010, 1033, https://doi.org/10.1002/ejoc.200901403.

[45] a) A. Chougnet, K. Liu, W.-D. Woggon, Chimia 2010, 64, 303, https://doi.org/10.2533/chimia.2010.303; b) E. C. Constable, C. E. Housecroft, M. Creus, K. Gademann, B. Giese, T. R. Ward, W.-D. Woggon, A. Chougnet, Chimia 2010, 64, 846, https://doi.org/10.2533/chimia.2010.846; c) D. Woggon, A. Chougnet, Chimia 2010, 64, 853, https://doi.org/:10.2533/chimia.2010.853; d) K. Gademann, A. Pfaltz, H. E. Wegner, H. Wennemers, W.-D. Woggon, A. Chougnet, Chimia 2010, 64, 859 , https://doi.org/10.2533/chimia.2010.859; $\quad$ e) D. Woggon, A. Chougnet, Chimia 2010, 64, 865 https://doi.org/10.2533/chimia.2010.865.

[46] J. Chapelat, U. Hengartner, A. Chougnet, K. Liu, P. Huebbe, G. Rimbach, W.-D. Woggon, ChemBioChem 2011, 12, 118 , https://doi.org/10.1002/cbic.201000511.

[47] W. Aeschimann, S. Staats, S. Kammer, N. Olieric, J.-M. Jeckelmann, D. Fotiadis, T. Netscher, G. Rimbach, M. Cascella, A. Stocker, Sci. Rep. 2017, 7 , 4970, https://doi.org/10.1038/s41598-017-05148-9.

[48] A. F.-P. Sonnen, H. Bakirci, T. Netscher, W. M. Nau, J. Am. Chem. Soc. 2005, 127, 15575, https://doi.org/10.1021/ja0543671.

[49] Supervision by Dr. E. Hungerbühler, Prof. G. Grundler, Prof. M. Hürzeler and Dr. C. Jablonski at the Fachhochschule Nordwestschweiz (FNHW), Institute for Chemistry and Bioanalytics, and by Prof. T. Spielmann, Zürcher Hochschule für Angewandte Wissenschaft (ZHAW), Department of Chemistry and Biological Chemistry.

\section{License and Terms}

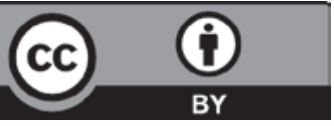

This is an Open Access article under the terms of the Creative Commons Attribution License CC BY 4.0. The material may not be used for commercial purposes.

The license is subject to the CHIMIA terms and conditions: (http:// chimia.ch/component/sppagebuilder/?view=page \&id=12).

The definitive version of this article is the electronic one that can be found at https://doi.org/10.2533/chimia.2021.957 